\title{
Endometriosis research using capture microdissection techniques: Progress and future applications (Review)
}

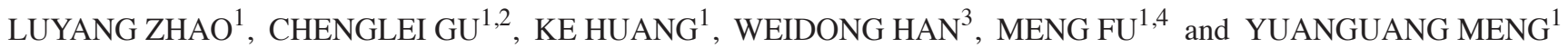 \\ ${ }^{1}$ Department of Gynecology and Obstetrics, Chinese People's Liberation Army (PLA) \\ Medical School, Chinese PLA General Hospital, Beijing 100853; ${ }^{2}$ Department of Gynecology and \\ Obstetrics, the 309th Hospital of the PLA, Beijing 100091; ${ }^{3}$ Department of Molecular Biology, Institute \\ of Basic Medicine, PLA Medical School, Chinese PLA General Hospital, Beijing 100853; ${ }^{4}$ Department of \\ Gynecology and Obstetrics, Haidian Maternal and Child Health Hospital, Beijing 100080, P.R. China
}

Received June 8, 2016; Accepted September 7, 2016

DOI: $10.3892 /$ br.2016.758

\begin{abstract}
Endometriosis is a common gynecological disease with high prevalence, while its etiology and pathophysiology have remained to be fully elucidated. Previous evidence suggested that this disorder may be in part or completely of somatic origin. However, traditional endometrial samples may not be ideal for investigation, as target cells, including epithelial and stromal cells, in endometriotic lesions are too sparse to be analyzed. Recently, capture microdissection techniques have been used to overcome these limitations and eliminate tissue heterogeneity in endometriosis research. Therefore, the present review summarized the alterations in epithelial and stromal cells in endometriosis tissues isolated through capture microdissection, outlined recent progress and provided directions for future investigation of the pathogenesis of endometriosis.
\end{abstract}

\section{Contents}

1. Introduction

2. Recent progress in endometriosis research using capture microdissection techniques

3. Current problems and future directions

4. Conclusions

\section{Introduction}

Endometriosis is a chronic and inflammatory disorder caused by the presence of endometrial tissues, including endometrial

Correspondence to: Dr Yuanguang Meng, Department of Gynecology and Obstetrics, Chinese People's Liberation Army (PLA) Medical School, Chinese PLA General Hospital, 28 Fuxing Road, Beijing 100853, P.R. China

E-mail: meng6512@vip.sina.com

Key words: endometriosis, microdissection, clonality analysis, loss of heterozygosity, somatic copy number alteration glandular and stromal cells, outside the uterine cavity. As one of the most common gynecological diseases, it affects 6-10\% of women of reproductive age (1). As the time from the onset of symptoms to diagnosis of the disease is 6-12 years, patients with endometriosis receive delayed treatment (2). Despite its high prevalence, the etiology and pathophysiology have remained to be fully elucidated.

The pathogenesis of endometriosis is generally explained using Sampson's retrograde menstruation theory. This theory suggests that endometrial cells are implanted into the peritoneum or pelvic organs through reflux via fallopian tubes during menstruation and is supported by several lines of evidence. Epidemiological studies showed that a long menstrual duration (menstrual flow at least 6 days per month) and short menstruation periods (less than 27 days) are risk factors for endometriosis (3). Mullerian anomalies, hematocolpos and hematometra also increase the likelihood of endometriosis (4). In baboons, intrapelvic injection of menstrual endometrium has been shown to cause peritoneal endometriosis (5). In addition, transtubal passage of endometrial cells into the peritoneal cavity was found to occur after uterine lavage and hysteroscopy (6). However, while the prevalence of retrograde menstruation has been observed in $76-90 \%$ of reproductive age women by laparoscopy examination during menstruation (7-9), endometriosis only develops in 6-10\% (1).

The occurrence of endometriosis in only a small proportion of women who had retrograde menstruation may be due to unique characteristics of their endometrial fragments, which have a key role in the pathogenesis of this disease. Thus far, intrinsic differences have been detected among ectopic and eutopic endometrium in endometriosis, and normal endometrium in controls (10). However, endometrial samples used in numerous studies may not be ideal (11), biopsy samples showing the 'typical' macroscopic appearance of endometriotic lesions cannot be confirmed under the microscope, and areas that appear 'normal' may turn out to be endometriotic at the microscopic level (12). Moreover, endometriotic glands may be too sparse to analyze even in tissues with consistent macroscopic and microscopic findings (13); hence, it is difficult to detect distinct genetic alterations, and failure to capture the target tissue may lead to unreliable 
results. In addition, although cell culture approaches are suitable for homogeneous cells, isolation of the cells from their natural tissue habitat and culture under artificial conditions represent confounding factors (14). To overcome these limitations and eliminate tissue heterogeneity in endometriosis research, capture microdissection techniques, including manual capture microdissection (MCM) and laser capture microdissection (LCM) are used. Capture microdissection provides accurate and reliable acquisition of target cells from specific microscopic regions, minimizes the possibility of contamination and allows for molecular genetic analysis of pure populations of epithelial and stromal cells in ectopic or eutopic endometrium.

This review summarizes recent advances in endometriosis research using capture microdissection approaches and discusses how these techniques can be improved and utilized in future studies.

\section{Recent progress in endometriosis research using capture microdissection techniques}

Clonality analysis. Clonality analysis is used to study the development of tumors and malignancies and identify their neoplastic characteristics (15). Monoclonality is an important feature of cancer cells. Previous studies reported that epithelial cells in endometrial cysts show monoclonal expansion; however, sampling methods involving scraping or peeling of the inner lining wall of ovarian cysts are relatively harsh (16). Recent studies using MCM or LCM concluded that ectopic epithelial cells are monoclonal in $82-100 \%$ of informative samples (17-21) (Table I). By contrast, Mayr et al (22) found that only two out of 32 samples $(6.3 \%)$ were monoclonal (Table I). Thus, no definitive evidence is available to classify endometriosis as a pre-malignant condition. Although clonality analysis in endometriosis has progressed, it has certain limitations. Paraffin-embedded specimens and human androgen receptor gene assay (HUMARA)-based assays are associated with potential damage or contamination of DNA, resulting in amplification bias, which can affect the accuracy and reproducibility of the results (22). In addition, several studies indicated that although each endometriotic focus has a monoclonal origin, different foci may have independent origins (19). Thus, 'clonal patches' may exist in terms of neighboring foci within a scope exhibiting the same monoclonality. Future clonal analyses should consider these phenomena and the possibility that stromal cells may have different clonal origins from epithelial cells.

Additionally, it is worth mentioning that whether genomic alterations occur in the functional and/or basal layer of the endometrium prior to menstrual reflux remains ambiguous. The functional layer of the endometrium can regenerate at each menstrual cycle and can thus easily disrupt the genomic integrity of the endometrium. However, increasingly sophisticated clonality analysis has been associated with the proposal of the 'stem cell theory of endometriosis'. Based on the regenerative physiological characteristics of endometrium, it has been suggested that endometrial stem cells may be derived from the basal layer of the uterus (23). Future studies on the etiology of endometriosis should focus on functional as well as basal layers of endometria.
Loss of heterozygosity ( $\mathrm{LOH}$ ) analysis. $\mathrm{LOH}$ refers to a gross chromosomal event that leads to loss of the entire gene and the surrounding chromosomal region (24). This event is often regarded as a mechanism for disabling tumor suppressor genes (TSGs) during the process of oncogenesis (25). However, numerous individuals with such a loss remain healthy, as they retain one functional gene on the other paired chromosome. Although LOH has been extensively investigated in ovarian cancer, this phenomenon has been rarely studied and is inconsistent in solitary endometriosis (17,26-33) (Table II). $\mathrm{LOH}$ at locus 10q23.3 is associated with phosphatase and tensin homolog (PTEN), which is one of the most studied TSGs (26,30-34). The PTEN gene encodes phosphatase, which inhibits apoptosis mediated by protein kinase $B$ and participates in cellular signal transduction, leading to enhanced cell proliferation and survival. Sato et al (26) and Ali-Fehmi et al (31) detected $\mathrm{LOH}$ at 10q23.3 in 56.5 and $29 \%$ of endometriosis cases, respectively. In these studies, three specific loci on chromosome 10 were identified to exhibit the highest frequencies of $\mathrm{LOH}$, leading to inactivation of the PTEN gene. Additionally, a previous genome-wide linkage study comprising 1,176 families conducted by Treloar et al (34) reported a region of significant linkage on chromosome 10q. Hence, alterations in PTEN are likely to result in endometriosis.

Furthermore, the locus associated with TP53 is among the most commonly investigated gene locations; However, thus far, TP53 mutations have only been found in endometriosis specimens coexisting with carcinoma but not in solitary endometriotic lesions $(17,28,32,33)$. In addition, Saare et al (35) revealed three copy neutral $\mathrm{LOH}$ regions in eleven different individuals. However, comparison of DNA from endometriotic lesions with endometrial or blood DNA revealed no foci-specific regions. Goumenou et al (28) and Prowse et al (30) observed that the frequency of genetic changes in endometriotic lesions increased from mild- to severe-stage endometriosis, suggesting that LOH events may have an important role in the development of this disorder. However, Wang et al (33) found no significant difference in the frequency of $\mathrm{LOH}$ between minimal-mild and moderate-severe stages of endometriosis, suggesting that the detected changes are associated with the development as well as progression of endometriosis.

In summary, the highest LOH frequencies were detected on chromosome 10q23.3 and the second-highest on chromosome 9p21. Results on other LOH events were inconsistent among the studies included in the present review and therefore require clarification by additional investigations. Although these data cannot fully support the hypothesis that endometriosis is a true neoplasm, they may imply that downregulation of certain TSGs in endometriosis is one mechanisms of endometriosis pathogenesis and is therefore worthy of further in-depth study.

Somatic copy number alteration (SCNA) and single nucleotide variation $(S N V)$ analyses. CNVs are thought to account for $\sim 1 \%$ of the variation between two individuals and single nucleotide polymorphisms (SNPs) are thought to account for $\sim 0.1 \%$ (36). While some certain CNVs and SNPs are common in the normal population, others are associated with the pathogenesis of specific disorders. In recent days, SCNAs and SNVs have attracted increased attention in endometriosis studies. 
Table I. Results of clonality analyses of microdissected ectopic endometrial tissues from endometriosis patients.

\begin{tabular}{lccr}
\hline Author, year & Samples/informative samples $(\mathrm{n})$ & Monoclonal samples, $\mathrm{n}(\%)$ & Assay \\
\hline Jiang, 1996 & $20 / 17$ & $14(82)$ & MCM/HUMARA \\
Tamura, 1998 & $25 / 10$ & $10(100)$ & MCM/PGK \\
Wu, 2003 & $40 / 38$ & $38(100)$ & LCM/HUMARA \\
Nabeshima, 2003 & $22 / 9$ (PGK) & $9(100)$ & LCM/HUMARA,PGK \\
Nabeshima, 2003 & $22 / 18$ (HUMARA) & $(20)$ \\
Mayr, 2003 & $29 / 13$ & $18(100)$ & LCM/HUMARA,PGK \\
Wang, 2010 & $50 / 34$ & $2(6)$ & LCM/PGK \\
\end{tabular}

MCM, manual capture microdissection; LCM, laser capture microdissection; HUMARA, human androgen receptor gene assay; PGK, phosphoglycerate kinase.

Table III summarizes the results of previous studies on SCNAs and SNVs (29,34,37-41). In 1999, Gogusev et al (37) first used comparative genomic hybridization $(\mathrm{CGH})$ to detect copy number alterations in 15 out of 18 manually dissected endometriotic tissues. In this study, genomic losses predominated in the majority of the samples. This finding was confirmed by follow-up studies, which showed that TSG inactivation is a critical event in endometriosis development $(29,40)$. In subsequent studies, CGH was performed in the endometriosis-derived cell line FbEM-1 and in original endometriotic tissues; the results suggested that chromosomal instability is important in the endometriosis pathogenesis. Guo et al (29) found that in all of the five patients selected, genomic alterations were present, mainly in the eutopic and ectopic endometria. Wu et al (39) accurately and consistently classified tissue samples into peritoneal implants and ovarian cysts by using cluster analysis of the genomic profile. Classification of tissue samples into two groups suggested that different sub-types of endometriosis may exhibit distinct genomic alteration profiles. Shared alterations are likely to be responsible for increased propensity of endometrial debris to be implanted at ectopic sites and for early events leading to establishment of lesions. Silveira et al (40) detected common genomic alterations in two cellular components (stromal and epithelial cells), suggesting that stromal-epithelial cell interactions are essential in normal as well as in pathological endometrial tissues. Furthermore, the high frequency of common genetic alterations in the two cell components at different anatomical sites provides evidence for the clonal origin of endometriotic lesions. Saare et al (35) used SNP arrays for comparing genomic alterations in eutopic and ectopic endometria with those in DNA extracted from the blood of the same individual. The result showed no unique SCNAs in the group of patients with endometriosis. This finding is partially consistent with a subsequent study by our group (41), in which a whole-exome sequencing was performed to search for somatic mutations in eutopic and ectopic endometria of patients with endometriosis and normal control patients. Although numerous distinct genes were mutated in eutopic and ectopic endometrial cells, no overlapping SNVs were identified between them.

To date, despite the various chromosomal alterations detected, few of these changes have been observed by more than one study. Of particular concern is that no specific de novo SCNAs or SSNVs are present in ectopic and ectopic endometria. One explanation is that certain molecular mechanisms such as epigenetic changes rather than SCNAs or SSNVs are most likely to contribute to the pathogenesis of endometriosis. The other explanation is that the previous studies did not provide sufficient information to confidently predict the full spectrum of mutations due to relatively limited sample sizes. Moreover, whether genomic alterations occur in the functional or basal layer of the endometrium remains ambiguous. Therefore, it remains impossible to draw any definite conclusions. Future studies with large sample size may identify de novo mutations in ectopic, eutopic and normal endometria (functional as well as basal layers) and simultaneously perform epigenomics investigations.

Transcriptome. At the transcript level, gene expression in ectopic and eutopic endometria from patients with endometriosis significantly differs from that in healthy women (42). Twelve studies that used LCM identified endometriosis-related differentially expressed genes (DEGs) (43-54). According to their biological functions, positive DEGs can be assigned to the following categories: Proliferation and apoptosis, pain pathway, hormones and steroids, adhesion and implantation, and DNA methylation, with parts of the gene functions overlapping (Table IV).

Matsuzaki et al $(43,45,47)$ applied a DNA microarray method in a series of studies on endometriosis. Comparison between samples of ectopic and eutopic endometria from patients revealed several DEGs in epithelial and stromal cells. The results indicated the involvement of the RAS/RAF/mitogen-activated protein kinase and phosphoinositide-3-kinase signaling pathways in the pathophysiology of deep infiltrating endometriosis (DIE) and ovarian endometriosis (OE). Although OE shared certain molecules with DIE, the expression patterns of genes involved in hormone regulation differed between these two types.

Microarray data revealed that three candidate genes, namely tyrosine kinase receptor $\mathrm{B}(\operatorname{TrKB}), \mu$-opioid receptor (MOR) and serotonin transporter, are potentially involved in pain pathways of endometriosis (43). All of the three genes were upregulated in DIE compared with the matched eutopic endometrium. The roles of TrKB and MOR were validated in a subsequent study on patients treated with 


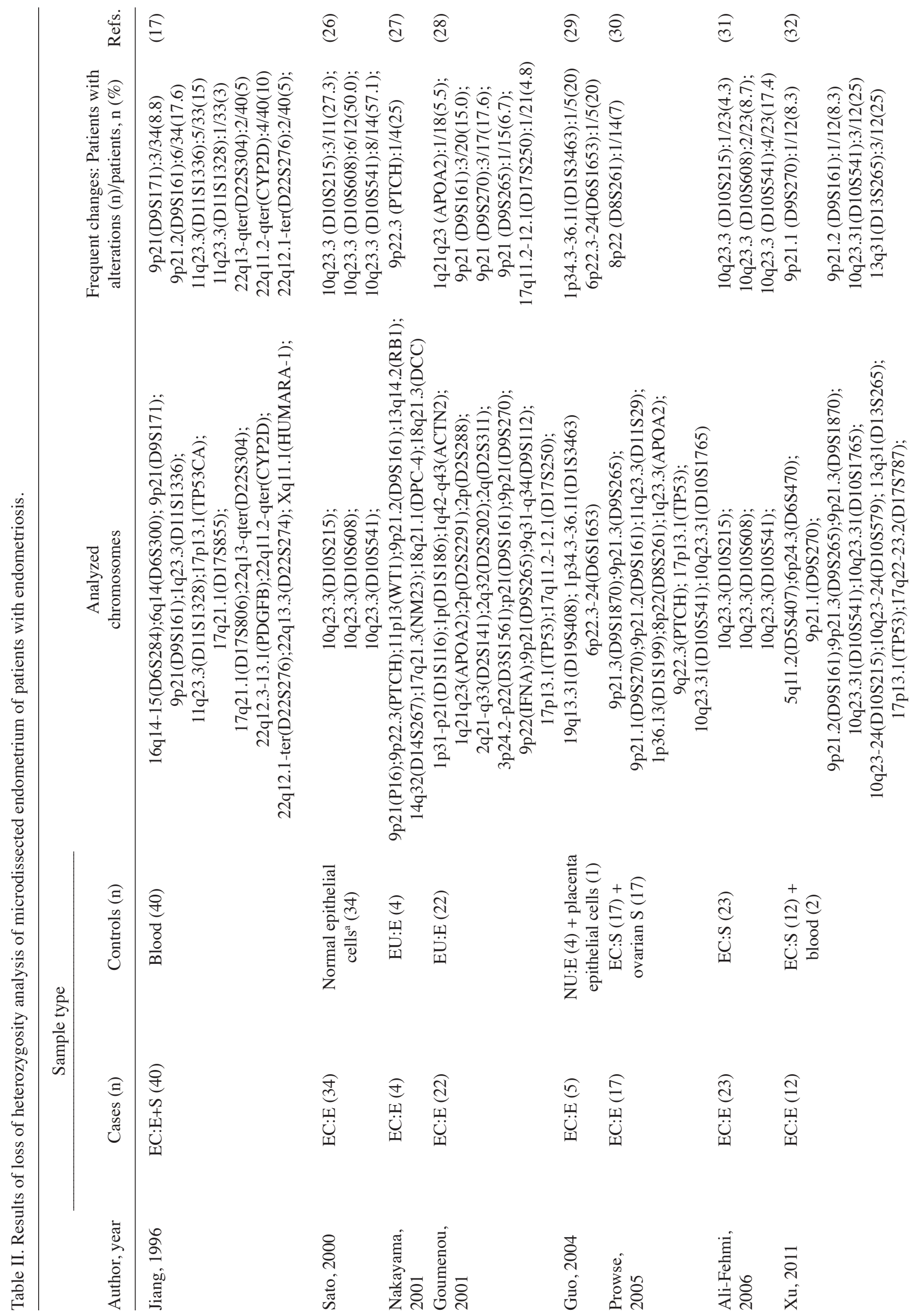


gonadotropin-releasing hormone agonist and progestin as cases and untreated patients as controls (50).

The two aromatase expression regulators chicken ovalbumin upstream promoter transcription factor 2 (COUP-TF2) and prostaglandin E2 receptor subtype EP3 (PGE2EP3) were evaluated by microarray analyses $(43,47)$. Downregulation of PGE2EP3 was detected in endometriosis epithelial cells from patients with OE and DIE, which may have increased the local production of estrogen in these cells. Of note, the expression of COUP-TF2 was found to differ between OE and DIE. In contrast to the result for DIE, the expression of COUP-TF2 was detected to be significantly higher in OE than in matched eutopic endometrium. A subsequent study on estrogen metabolism revealed that the mRNA expression of aromatase was significantly higher in epithelial cells than that in stromal cells of eutopic and ectopic endometria obtained from patients with endometriosis (43). Moreover, in epithelial cells from eutopic endometrial and ectopic endometriotic samples, the mRNA expression levels of 17- $\beta$-hydroxysteroid dehydrogenase type 2 during the early, middle and late secretory phases were significantly increased compared with those in the late proliferative phase, while no significant cyclical differences were detected in eutopic endometrium (46). These findings suggested that in epithelial cells in the ectopic endometrium, the local estrogen concentration may be higher than that in stromal cells, irrespective of the menstrual cycle phase.

Considering molecular defects in the endometrium involved in implantation and endometriosis-associated infertility, Matsuzaki et al (52) investigated the different expression patterns of homeobox A10 (HOXA10) between patients with endometriosis and fertile controls. The results showed that the mRNA and protein expression levels of HOXA10 in endometrial stromal cells were significantly lower in infertile patients with endometriosis than those in fertile controls. In another study, Matsuzaki et al (53) analyzed two further implantation-associated factors, namely E-cadherin and $\beta$-catenin. The levels of these two proteins were significantly higher in the mid-secretory endometrium of infertile patients with endometriosis compared with those in healthy fertile controls. This finding indicated that altered expression of HOXA-10 in endometrial stromal cells and impaired downregulation of E-cadherin and $\beta$-catenin proteins in epithelial cells are potential molecular mechanisms associated with infertility in patients with endometriosis. Matrix metalloproteinase-7 (MMP-7), a member of the MMP family, cleaves extracellular matrix components in normal physiological and pathological processes. A study revealed that the expression levels of MMP-7 in DIE were significantly higher than those in ovarian and superficial peritoneal types (54). Thus, the MMP-7 gene appears to significantly vary among different types of endometriosis and represents a useful marker for discriminating between them.

Three DNA methyltransferases (DNMT), namely DNMT1, DNMT3A and DNMT3B, cooperatively maintain DNA methylation and are overexpressed in ectopic endometrium compared with that in normal control subjects or eutopic endometrium from women with endometriosis (51). Hence, the pathology of endometriosis may be epigenetic.

While the scope of gene function research is broad, only 28 DEGs have been identified in endometriosis research using 
Table III. Results of genome-wide copy number variation and single nucleotide variation analysis of microdissected endometrium of patients with endometriosis.

\begin{tabular}{|c|c|c|c|c|c|c|}
\hline Author, year & $\begin{array}{l}\text { Samples } \\
\text { (n) }\end{array}$ & $\begin{array}{l}\text { Patients with } \\
\text { alterations } \\
\text { (n/total) }\end{array}$ & Total CNVs/SNVs & Frequent changes & Methods & Refs. \\
\hline Gogusev, 1999 & EC (18) & $15 / 18$ & 59 & $\begin{array}{c}\text { G: 6q, 7q, 17q; } \\
\text { L: 1p, 5p, 6q,7p14-22qter, } \\
22 \mathrm{q} 12.3 \text {-qter, } 9 \mathrm{q}, 16 \mathrm{q}, 17 \mathrm{q}\end{array}$ & $\mathrm{MCM}, \mathrm{CGH}$ & $(37)$ \\
\hline Gogusev, 2000 & $\begin{array}{l}\text { FbEM1 cell line } \\
\quad+\text { original } \\
\text { endometriotic } \\
\text { sample (1) }\end{array}$ & $1 / 1$ & 66 & $\begin{array}{c}\text { G: } 1,2,3,5,6 \mathrm{p}, 7 \\
\text { 16, 17, 20,21q, } 22 \mathrm{q} \\
\text { L: } 6 \mathrm{q}, 9,11 \mathrm{p}, \\
12,13 \mathrm{q}, 18, \mathrm{X}\end{array}$ & $\mathrm{MCM}, \mathrm{CGH}$ & $(38)$ \\
\hline Guo, 2004 & $\mathrm{EU}(5)+\mathrm{NU}(4)$ & $5 / 5$ & 68 & $\begin{array}{c}\text { G: } 3 p, 10 q, 3 q \\
\text { L: } 1 p, 3 p, 4 p, 22 q\end{array}$ & LCM, aCGH & (29) \\
\hline Wu, 2006 & $E C(5)+E U(5)$ & $5 / 5$ & $810(\mathrm{EC})+745(\mathrm{EU})$ & $\begin{array}{l}\mathrm{G}: 1 \mathrm{p}, 5 \mathrm{p}, 6 \mathrm{p}+\mathrm{q}, 11 \mathrm{p}, \mathrm{Xq} \\
\mathrm{L}: 1 \mathrm{p}, 5 \mathrm{p}, 6 \mathrm{q}, 16 \mathrm{q}\end{array}$ & LCM, aCGH & (39) \\
\hline Saare, 2012 & $\begin{array}{c}\text { EC }(17)+\text { EU (11) } \\
+ \text { blood (11) }\end{array}$ & $0 / 11$ & No de novo SCNAs & & LCM, aSNP & (35) \\
\hline Silveria, 2012 & $\mathrm{EC}(20)+\mathrm{EU}(3)$ & $8 / 8$ & 119 & $\begin{array}{c}\text { G: 1q21-q23, 11q12-q21; } \\
\text { L: 3p24-p25, 5q34, 7p14-p21, } \\
\text { 9p21, 11q23q24, 16q22-q23, } \\
\text { 18q12-q21, 18q22-q23, 9q13 }\end{array}$ & $\begin{array}{l}\text { LCM, } \\
\text { HR-CGH }\end{array}$ & (40) \\
\hline Li, 2014 & $\begin{array}{l}\mathrm{EC}(16)+\mathrm{EU}(16)+ \\
\mathrm{NU}(5)+\text { blood (16) }\end{array}$ & $16 / 16$ & $\begin{array}{l}\text { No overlapped } \\
\text { SSNVs }\end{array}$ & & LCM,WES & (41) \\
\hline
\end{tabular}

microdissection techniques. Research has not only focused on elucidating the underlying molecular mechanisms of endometriosis but also on its clinical symptoms, such as pain and infertility. Analysis of specific molecular markers is one potential option for non-invasive diagnosis of endometriosis, which may also be utilized as molecular targets for its selective and efficient treatment and prevention.

\section{Current problems and future directions}

Several lines of evidence have indicated that genomic alterations in the endometrium are essential for the development of endometriosis. However, the precise molecular mechanisms underlying the pathogenesis of endometriosis remain elusive. Based on the current progress in endometriosis research, two interesting topics are discussed here. Clear interpretation of these issues can provide experiences to other investigators and anticipate future directions in endometriosis research.

Hypothesis-based versus hypothesis-free research. Studies of endometriosis-associated genes are classified into hypothesis-based and hypothesis-free approaches (55). Hypothesis-based candidate gene studies rely on previous hypotheses or knowledge of the disease. For this, several genes are selected based on their inferred biological functions. This approach remains commonplace due to limited funds and the large number of genes available. The majority of the studies on LOH and DEGs included in the present review are hypothesis-based studies. However, the current knowledge of the biological mechanisms of endometriosis is very basic, and the value of hypothesis-based studies is therefore limited. It may thus be inferred that hypothesis-based studies are only suitable for verifying the outcomes of hypothesis-free approaches using large samples of cases and controls. Hypothesis-free studies search the entire genome to identify disease-predisposing genes without prior knowledge of their functional relevance and are thus suitable for identifying genes linked to endometriosis.

In the present review, three important methods, namely CGH, SNP array and whole exome sequencing (WES), which were used in previous studies to detect alterations associated with endometriosis without prior knowledge of specific regions of interest, were compared. The use of the traditional CGH method has detected numerous cryptic gains and/or losses of chromosomal regions in endometriosis samples. However, the application of CGH has been hampered by limited resolution and low throughput. The SNP array and WES can offer accurate and high-throughput detection. However, in studies by Saare et al (35) and Li et al (41), de novo somatic mutation was not identified in endometriosis after excluding germ-line mutations. In spite of this, effective and precise hypothesis-free technology for 
Table IV. Differentially expressed genes in microdissected endometrium of patients with endometriosis.

\begin{tabular}{|c|c|c|c|c|c|c|c|c|c|c|}
\hline \multirow[b]{2}{*}{ Author, year } & \multirow[b]{2}{*}{ Gene function } & \multirow[b]{2}{*}{ mRNA } & \multicolumn{2}{|c|}{$\begin{array}{l}\text { Cases } \\
(\mathrm{n})\end{array}$} & \multicolumn{2}{|c|}{$\begin{array}{l}\text { Controls } \\
\text { (s) }\end{array}$} & \multirow[b]{2}{*}{ Type studied } & \multicolumn{2}{|c|}{$\begin{array}{l}\text { Expression } \\
\text { change }\end{array}$} & \multirow[b]{2}{*}{ Refs. } \\
\hline & & & $\mathrm{EC}$ & $\mathrm{EU}$ & $\mathrm{EU}$ & $\mathrm{NE}$ & & $\mathrm{E}$ & S & \\
\hline Matsuzaki, 2004 & $\begin{array}{l}\text { Cell proliferation } \\
\text { and apoptosis }\end{array}$ & PDGFRA & 12 & - & 12 & - & DIE & - & $\uparrow$ & (43) \\
\hline Matsuzaki, 2006 & & & 12 & - & 12 & - & $\mathrm{OE}$ & - & $\uparrow$ & (47) \\
\hline Matsuzaki, 2004 & & PKC $\beta 1$ & 12 & - & 12 & - & DIE & - & $\uparrow$ & (43) \\
\hline Matsuzaki, 2006 & & & 12 & - & 12 & - & $\mathrm{OE}$ & - & $\uparrow$ & (47) \\
\hline Matsuzaki, 2004 & & JAK1 & 12 & - & 12 & - & DIE & - & $\uparrow$ & (43) \\
\hline Matsuzaki, 2006 & & & 12 & - & 12 & - & $\mathrm{OE}$ & - & $\uparrow$ & (47) \\
\hline Matsuzaki, 2004 & & Sprouty2 & 12 & - & 12 & - & DIE & - & $\uparrow$ & (43) \\
\hline Matsuzaki, 2006 & & & 12 & - & 12 & - & DIE & - & $\uparrow$ & (47) \\
\hline Matsuzaki, 2004 & & MKK7 & 12 & - & 12 & - & DIE & - & $\uparrow$ & (43) \\
\hline Gaeje, 2007 & & WNT7A & 20 & - & 8 & - & NR & $\uparrow$ & $\uparrow$ & (49) \\
\hline Matsuzaki, 2005 & & MSP & 26 & - & 23 & - & DIE & $\uparrow$ & - & (45) \\
\hline Matsuzaki, 2005 & & & 14 & - & 26 & - & DIE & $\uparrow$ & - & (45) \\
\hline Matsuzaki, 2005 & & RON & 12 & - & - & 12 & DIE & $\uparrow^{\mathrm{a}}$ & - & (44) \\
\hline Matsuzaki, 2005 & & SOS & 12 & - & - & 12 & DIE & $\uparrow^{\mathrm{a}}$ & - & (44) \\
\hline Matsuzaki, 2005 & & 14-3-3 protein eta & 12 & - & - & 12 & DIE & $\uparrow^{\mathrm{a}}$ & - & (44) \\
\hline Matsuzaki, 2005 & & uPAR & 12 & - & - & 12 & DIE & $\uparrow^{\mathrm{a}}$ & - & (44) \\
\hline Matsuzaki, 2005 & & KSR & 12 & - & - & 12 & DIE & - & $\uparrow^{\mathrm{a}}$ & (44) \\
\hline Matsuzaki, 2005 & & $\begin{array}{l}\text { PI3K p85 regulatory } \\
\text { subunit } \alpha\end{array}$ & 12 & - & - & 12 & DIE & - & $\uparrow^{\mathrm{a}}$ & (44) \\
\hline Matsuzaki, 2004 & Pain pathway & $\operatorname{TrKB}$ & 12 & - & 12 & - & DIE & $\uparrow$ & - & (43) \\
\hline Matsuzaki, 2007 & & & $12^{\mathrm{b}}$ & - & - & $12^{\mathrm{c}}$ & DIE & $\uparrow$ & - & (50) \\
\hline Matsuzaki, 2004 & & MOR & 12 & - & 12 & - & DIE & - & $\uparrow$ & (43) \\
\hline Matsuzaki, 2006 & & & 12 & - & 12 & - & $\mathrm{OE}$ & - & $\uparrow$ & (47) \\
\hline Matsuzaki, 2007 & & & $12^{\mathrm{b}}$ & - & - & $12^{\mathrm{c}}$ & DIE & - & $\uparrow$ & (50) \\
\hline Matsuzaki, 2004 & & $5 \mathrm{HTT}$ & 12 & - & 12 & - & DIE & - & $\uparrow$ & (43) \\
\hline Matsuzaki, 2006 & $\begin{array}{l}\text { Hormones } \\
\text { and steroids }\end{array}$ & Aromatase & 16 & 30 & - & 24 & DIE & $\uparrow$ & - & (46) \\
\hline Matsuzaki, 2006 & & $17 \beta-H S D 2$ & - & 30 & - & 24 & DIE & $\uparrow$ & - & (46) \\
\hline Matsuzaki, 2006 & & & 12 & - & 12 & - & $\mathrm{OE}$ & $\uparrow$ & - & (47) \\
\hline Matsuzaki, 2004 & & HSP90A & 12 & - & 12 & - & DIE & $\uparrow$ & - & (43) \\
\hline Matsuzaki, 2004 & & COUP-TF2 & 12 & - & 12 & - & DIE & $\uparrow$ & - & (43) \\
\hline Matsuzaki, 2006 & & & 12 & - & 12 & - & $\mathrm{OE}$ & $\uparrow$ & - & (47) \\
\hline Matsuzaki, 2004 & & PGE2EP3 & 12 & - & 12 & - & DIE & $\uparrow$ & - & (43) \\
\hline Matsuzaki, 2006 & & & 12 & - & 12 & - & $\mathrm{OE}$ & $\uparrow$ & - & (47) \\
\hline Matsuzaki, 2009 & $\begin{array}{l}\text { Adhesion and } \\
\text { implantation }\end{array}$ & HOXA10 & - & 62 & - & 20 & $\mathrm{OE}+\mathrm{DIE}+\mathrm{PE}$ & - & $\uparrow^{\mathrm{d}}$ & (52) \\
\hline Matsuzaki, 2010 & & E-cadherin & - & 151 & - & 51 & NR & $\uparrow^{\mathrm{d}}$ & - & (53) \\
\hline Matsuzaki, 2010 & & $\beta$-catenin & - & 151 & - & 51 & NR & $\uparrow^{d}$ & - & (53) \\
\hline Matsuzaki, 2010 & & MMP-7 & 137 & & - & 50 & DIE & $\uparrow$ & - & (54) \\
\hline $\mathrm{Wu}, 2006$ & DNA methylation & DNMT1 & 13 & & 10 & 8 & $\mathrm{OE}+\mathrm{DIE}+\mathrm{PE}$ & $\uparrow$ & - & (48) \\
\hline $\mathrm{Wu}, 2006$ & & DNMT3A & 13 & & 10 & 8 & $\mathrm{OE}+\mathrm{DIE}+\mathrm{PE}$ & $\uparrow$ & - & (48) \\
\hline Wu, 2006 & & DNMT3B & 13 & & 10 & 8 & $\mathrm{OE}+\mathrm{DIE}+\mathrm{PE}$ & $\uparrow$ & - & (48) \\
\hline
\end{tabular}

${ }^{a}$ In the late secretory phase; ${ }^{b}$ from GnRH agonist- and progestin-treated patients; ${ }^{\circ}$ from EC in untreated patients; ${ }^{\text {din }}$ infertile patients. EC, ectopic endometrium; EU, eutopic endometrium; NE, normal endometrium; E, epithelial glandular cell; S, stromal cell; DIE, deep infiltrating endometriosis; OE, ovarian endometriosis; PE, peritoneal endometriosis; NR, not recorded; PDGFRA, platelet-derived growth factor receptor alpha; PKC, protein kinase C; JAK, Janus kinase; MKK7, mitogen-activated protein kinase kinase 7; MSP, major sperm protein; RON, macrophage-stimulating protein receptor; SOS, Son of sevenless; Upar, Urokinase receptor; KSR, kinase suppressor of RAS; PI3K, phosphoinositide-3 kinase; TrKb, tropomyosin receptor kinase B; MOR, middle operon regulator; 5HTT, serotonin transporter gene; 17 $\beta$-HSD2, 17ß-hydroxysteroid dehydrogenase type 2; HSP, heat shock protein; COUP-TF2, chicken ovalbumin upstream promoter transcription factor 2. 
'omics' sequencing, such as single-cell RNA sequencing and whole-genome sequencing, may be used to elucidate the pathogenesis of endometriosis, determine useful biomarkers and develop potential target therapies.

Applications of capture microdissection techniques in endometriosis. The capture microdissection technology was first described in the early 20th century and has been progressively optimized in recent years. During MCM, defined cell populations are manually cut out from tissue sections under the microscope. Although this method is feasible for isolation of specific cells, it proved to be inefficient and time consuming (56). LCM was then broadly used in a wide variety of applications. Typical endometriotic lesions contain variable amounts of surrounding tissue in addition to endometrial glands and stromal cells. Therefore, the LCM approach, which allows for separation of a population of purified endometriotic cells, may aid in revealing the true alterations characteristic of endometriosis. Despite the obvious advantages, LCM has certain limitations worth mentioning. First, the products extracted after LCM for downstream experiments may be imperfect. For example, DNA extracted after LCM is usually fragmented, which may lead to certain low-confidence changes in array analysis (57). Furthermore, the amount of DNA yielded by LCM is insufficient for high-throughput genetic analyses. Therefore, whole-genome amplification (WGA) is necessary for downstream experiments. However, amplification artifacts generated by WGA can create false deletions and duplications and distort the initial template (58). Furthermore, the small amount of DNA/RNA obtained by LCM is prone to degradation during storage or processing. Second, the tissue section remains uncovered during microdissection. Without a cover slip, certain cellular details may be obscured at high magnifications, thus creating difficulties in the capture of particular cells (59). Third, certain dyes, including eosin, may interfere with proteomic tools such as two-dimensional polyacrylamide gel electrophoresis (60). Finally, certain target cells may be contaminated by the fragments of adjacent cells due to the restriction of laser spot size. In 2009, Matsuzaki et al (61) provided methods for obtaining RNA after LCM for endometirosis research, comprising a detailed introduction to the process of frozen sample preparation, staining, cutting, RNA extraction and quality assessment. Following these instructions, high-quality RNA was successfully extracted by our group for next generation sequencing (data not published) and the following experience in using LCM in endometriotic lesion was gained: i) Use of frozen tissue is recommended for obtaining DNA and RNA with high integrity, as isolation from formalin-fixed, paraffin-embedded tissue blocks may cause degradation, leading to non-uniformity in sample labeling with fluorescent nucleotides; ii) eosin staining is not necessary for identifying gland and stromal cells during LCM; iii) xylene used for dehydration may be replaced by $100 \%$ ethanol, particularly when using Leica membrane Frameslides; and iv) storage of laser-dissected cells at $-80^{\circ} \mathrm{C}$ for more than one a week is not recommended, as the extent of RNA degradation proportionally increases with the storage time. Overall, easy mastering, rapid collection and accurate capture of target cells make LCM an ideal tool for future research on endometriosis.

\section{Conclusions}

In the present review, advances in endometriosis research using capture microdissection techniques were presented. Evidence from 32 studies revealed various somatic alterations in ectopic and eutopic endometrosis tissues. These results enhance the current understanding of the pathogenesis of endometriosis and provide putative biomarkers as well as therapeutic targets. With the rapid advancement of detection technologies, future studies should take into account the use of the hypothesis-free method combined with microdissection techniques for precise analysis. For example, single-cell high-throughput sequencing combined with LCM can be used not only in genomics but also in transcriptomics and proteomics studies. Furthermore, hypothesis-based studies with an appropriate design and large sample size must be performed to confirm preliminary data from hypothesis-free studies. With the application of capture microdissection, great advances in the elucidation of the pathogenesis of endometriosis are expected in the near future.

\section{Acknowledgements}

The present study was supported by the National Natural Science Foundation of China (no. 81571411).

\section{References}

1. Giudice LC and Kao LC: Endometriosis. Lancet 364: 1789-1799, 2004.

2. Hudelist G, Fritzer N, Thomas A, Niehues C, Oppelt P, Haas D, Tammaa A and Salzer H: Diagnostic delay for endometriosis in Austria and Germany: Causes and possible consequences. Hum Reprod 27: 3412-3416, 2012.

3. Darrow SL, Vena JE, Batt RE, Zielezny MA, Michalek AM and Selman S: Menstrual cycle characteristics and the risk of endometriosis. Epidemiology 4: 135-142, 1993.

4. Olive DL and Henderson DY: Endometriosis and mullerian anomalies. Obstet Gynecol 69: 412-415, 1987.

5. D'Hooghe TM, Bambra CS, Raeymaekers BM, De Jonge I, Lauweryns JM and Koninckx PR: Intrapelvic injection of menstrual endometrium causes endometriosis in baboons (Papio cynocephalus and Papio anubis). Am J Obstet Gynecol 173: 125-134, 1995.

6. Lübke F: 'Principles and practice of hysteroscopy'. Acta Eur Fertil 17: 413-416, 1986

7. Blumenkrantz MJ, Gallagher N, Bashore RA and Tenckhoff H: Retrograde menstruation in women undergoing chronic peritoneal dialysis. Obstet Gynecol 57: 667-670, 1981.

8. Liu DT and Hitchcock A: Endometriosis: Its association with retrograde menstruation, dysmenorrhoea and tubal pathology. $\mathrm{Br}$ J Obstet Gynaecol 93: 859-862, 1986.

9. Halme J, Hammond MG, Hulka JF, Raj SG and Talbert LM: Retrograde menstruation in healthy women and in patients with endometriosis. Obstet Gynecol 64: 151-154, 1984.

10. Fassbender A, Burney RO, O DF, D'Hooghe T and Giudice L: Update on Biomarkers for the Detection of Endometriosis. Biomed Res Int 2015: 130854, 2015.

11. Fassbender A, Rahmioglu N, Vitonis AF, Viganò P, Giudice LC, D'Hooghe TM, Hummelshoj L, Adamson GD, Becker CM, Missmer SA, et al; WERF EPHect Working Group: World Endometriosis Research Foundation Endometriosis Phenome and Biobanking Harmonisation Project: IV. Tissue collection, processing, and storage in endometriosis research. Fertil Steril 102: 1244-1253, 2014.

12. Moen MH and Halvorsen TB: Histologic confirmation of endometriosis in different peritoneal lesions. Acta Obstet Gynecol Scand 71: 337-342, 1992.

13. Walter AJ, Hentz JG, Magtibay PM, Cornella JL and Magrina JF: Endometriosis: correlation between histologic and visual findings at laparoscopy. Am J Obstet Gynecol 184: 1407-1411; discussion 1411-1413, 2001. 
14. Datta S, Malhotra L, Dickerson R, Chaffee S, Sen CK and Roy S: Laser capture microdissection: Big data from small samples. Histol Histopathol 30: 1255-1269, 2015.

15. Partridge M, Pateromichelakis S, Phillips E, Emilion G and Langdon J: Profiling clonality and progression in multiple premalignant and malignant oral lesions identifies a subgroup of cases with a distinct presentation of squamous cell carcinoma. Clin Cancer Res 7: 1860-1866, 2001.

16. Jimbo H,Hitomi Y, Yoshikawa H, Yano T, Momoeda M, Yasugi T, Taketani Y and Esumi H: Clonality analysis of bilateral ovarian endometrial cysts. Fertil Steril 72: 1142-1143, 1999.

17. Jiang X, Hitchcock A, Bryan EJ, Watson RH, Englefield P, Thomas EJ and Campbell IG: Microsatellite analysis of endometriosis reveals loss of heterozygosity at candidate ovarian tumor suppressor gene loci. Cancer Res 56: 3534-3539, 1996.

18. Tamura M, Fukaya T, Murakami T, Uehara S and Yajima A Analysis of clonality in human endometriotic cysts based on evaluation of $\mathrm{X}$ chromosome inactivation in archival formalin-fixed, paraffin-embedded tissue. Lab Invest 78: 213-218, 1998.

19. Wu Y, Basir Z, Kajdacsy-Balla A, Strawn E, Macias V, Montgomery K and Guo SW: Resolution of clonal origins for endometriotic lesions using laser capture microdissection and the human androgen receptor (HUMARA) assay. Fertil Steril 79 (Suppl 1): 710-717, 2003.

20. Nabeshima H, Murakami T, Yoshinaga K, Sato K, Terada Y and Okamura K: Analysis of the clonality of ectopic glands in peritoneal endometriosis using laser microdissection. Fertil Steril 80: 1144-1150, 2003.

21. Wang S, Lang JH and Zhang RY: Clonal analysis of endometriotic lesions using human androgen receptor gene. Zhonghua Fu Chan Ke Za Zhi 45: 593-597, 2010 (In Chinese).

22. Mayr D, Amann G, Siefert C, Diebold J and Anderegg B: Does endometriosis really have premalignant potential? A clonal analysis of laser-microdissected tissue. FASEB J 17: 693-695, 2003 .

23. Leyendecker G, Herbertz M, Kunz G and Mall G: Endometriosis results from the dislocation of basal endometrium. Hum Reprod 17: 2725-2736, 2002.

24. Knudson AG: Hereditary cancer: Two hits revisited. J Cancer Res Clin Oncol 122: 135-140, 1996.

25. Joseph CG, Darrah E, Shah AA, Skora AD, Casciola-Rosen LA Wigley FM, Boin F, Fava A, Thoburn C, Kinde I, et al: Association of the autoimmune disease scleroderma with an immunologic response to cancer. Science 343: 152-157, 2014

26. Sato N, Tsunoda H, Nishida M, Morishita Y, Takimoto Y, Kubo T and Noguchi M: Loss of heterozygosity on 10q23.3 and mutation of the tumor suppressor gene PTEN in benign endometrial cyst of the ovary: Possible sequence progression from benign endometrial cyst to endometrioid carcinoma and clear cell carcinoma of the ovary. Cancer Res 60: 7052-7056, 2000

27. Nakayama K, Toki T, Nikaido T, Zhai YL and Konishi I: Genetic alterations in microsatellite marker sites among tumor suppressor genes in endometriosis. Gynecol Obstet Invest 51: 240-242, 2001

28. Goumenou AG, Arvanitis DA, Matalliotakis IM,Koumantakis EE and Spandidos DA: Microsatellite DNA assays reveal an allelic imbalance in p16(Ink4), GALT, p53, and APOA2 loci in patients with endometriosis. Fertil Steril 75: 160-165, 2001.

29. Guo SW, Wu Y, Strawn E, Basir Z, Wang Y, Halverson G Montgomery $\mathrm{K}$ and Kajdacsy-Balla A: Genomic alterations in the endometrium may be a proximate cause for endometriosis. Eur J Obstet Gynecol Reprod Biol 116: 89-99, 2004

30. Prowse AH, Fakis G, Manek S, Churchman M, Edwards S, Rowan A, Koninckx P, Kennedy S and Tomlinson IP: Allelic loss studies do not provide evidence for the 'endometriosis-as-tumor' theory. Fertil Steril 83 (Suppl 1): 1134-1143, 2005.

31. Ali-Fehmi R, Khalifeh I, Bandyopadhyay S, Lawrence WD Silva E, Liao D, Sarkar FH and Munkarah AR: Patterns of loss of heterozygosity at 10q23.3 and microsatellite instability in endometriosis, atypical endometriosis, and ovarian carcinoma arising in association with endometriosis. Int J Gynecol Pathol 25: 223-229, 2006

32. Xu B, Hamada S, Kusuki I, Itoh R and Kitawaki J: Possible involvement of loss of heterozygosity in malignant transformation of ovarian endometriosis. Gynecol Oncol 120: 239-246, 2011.

33. Wang DB, Ren FY and Ren F: Detecting and investigating the significance of high-frequency $\mathrm{LOH}$ chromosome regions for endometriosis-related candidate genes. Gynecol Endocrinol 28: 553-558, 2012
34. Treloar SA, Wicks J, Nyholt DR, Montgomery GW, Bahlo M, Smith V, Dawson G, Mackay IJ, Weeks DE, Bennett ST, et al: Genomewide linkage study in 1,176 affected sister pair families identifies a significant susceptibility locus for endometriosis on chromosome 10q26. Am J Hum Genet 77: 365-376, 2005.

35. Saare M, Sõritsa D, Vaidla K, Palta P, Remm M, Laan M, Karro H, Sõritsa A, Salumets A, D'Hooghe T, et al: No evidence of somatic DNA copy number alterations in eutopic and ectopic endometrial tissue in endometriosis. Hum Reprod 27: 1857-1864, 2012.

36. Iafrate AJ, Feuk L, Rivera MN, Listewnik ML, Donahoe PK, Qi Y, Scherer SW and Lee C: Detection of large-scale variation in the human genome. Nat Genet 36: 949-951, 2004.

37. Gogusev J, Bouquet de Jolinière J, Telvi L, Doussau M, du Manoir S, Stojkoski A and Levardon M: Detection of DNA copy number changes in human endometriosis by comparative genomic hybridization. Hum Genet 105: 444-451, 1999.

38. Gogusev J, Bouquet de Jolinière J, Telvi L, Doussau M, du Manoir S, Stojkoski A and Levardon M: Genetic abnormalities detected by comparative genomic hybridization in a human endometriosis-derived cell line. Mol Hum Reprod 6: 821-827, 2000.

39. Wu Y, Strawn E, Basir Z, Wang Y, Halverson G, Jailwala P and Guo SW: Genomic alterations in ectopic and eutopic endometria of women with endometriosis. Gynecol Obstet Invest 62: 148-159, 2006.

40. Silveira CG, Abrão MS, Dias JA Jr, Coudry RA, Soares FA, Drigo SA, Domingues MA and Rogatto SR: Common chromosomal imbalances and stemness-related protein expression markers in endometriotic lesions from different anatomical sites: The potential role of stem cells. Hum Reprod 27: 3187-3197, 2012.

41. Li X, Zhang Y, Zhao L, Wang L, Wu Z, Mei Q, Nie J, Li X, Li Y, Fu X, et al: Whole-exome sequencing of endometriosis identifies frequent alterations in genes involved in cell adhesion and chromatin-remodeling complexes. Hum Mol Genet 23: 6008-6021, 2014

42. Liu F, Lv X, Yu H, Xu P, Ma R and Zou K: In search of key genes associated with endometriosis using bioinformatics approach. Eur J Obstet Gynecol Reprod Biol 194: 119-124, 2015.

43. Matsuzaki S, Canis M, Vaurs-Barrière C, Pouly JL, Boespflug-Tanguy O, Penault-Llorca F, Dechelotte P, Dastugue B, Okamura K and Mage G: DNA microarray analysis of gene expression profiles in deep endometriosis using laser capture microdissection. Mol Hum Reprod 10: 719-728, 2004.

44. Matsuzaki S, Canis M, Pouly JL, Dechelotte P, Okamura K and Mage G: The macrophage stimulating protein/RON system: A potential novel target for prevention and treatment of endometriosis. Mol Hum Reprod 11: 345-349, 2005.

45. Matsuzaki S, Canis M, Vaurs-Barrière C, Boespflug-Tanguy O, Dastugue B and Mage G: DNA microarray analysis of gene expression in eutopic endometrium from patients with deep endometriosis using laser capture microdissection. Fertil Steril 84 (Suppl 2): 1180-1190, 2005.

46. Matsuzaki S, Canis M, Pouly JL, Déchelotte PJ and Mage G: Analysis of aromatase and 17beta-hydroxysteroid dehydrogenase type 2 messenger ribonucleic acid expression in deep endometriosis and eutopic endometrium using laser capture microdissection. Fertil Steril 85: 308-313, 2006.

47. Matsuzaki S, Canis M, Pouly JL, Botchorishvili R, Déchelotte PJ and Mage G: Differential expression of genes in eutopic and ectopic endometrium from patients with ovarian endometriosis. Fertil Steril 86: 548-553, 2006.

48. Wu Y, Strawn E, Basir Z, Halverson G and Guo SW: Promoter hypermethylation of progesterone receptor isoform B (PR-B) in endometriosis. Epigenetics 1: 106-111, 2006.

49. Gaetje R, Holtrich U, Karn T, Cikrit E, Engels K, Rody A and Kaufmann M: Characterization of WNT7A expression in human endometrium and endometriotic lesions. Fertil Steril 88: 1534-1540, 2007.

50. Matsuzaki S, Canis M, Pouly JL, Botchorishvili R, Déchelotte PJ and Mage G: Both GnRH agonist and continuous oral progestin treatments reduce the expression of the tyrosine kinase receptor B and mu-opioid receptor in deep infiltrating endometriosis. Hum Reprod 22: 124-128, 2007.

51. Wu Y, Strawn E, Basir Z, Halverson G and Guo SW: Aberrant expression of deoxyribonucleic acid methyltransferases DNMT1, DNMT3A, and DNMT3B in women with endometriosis. Fertil Steril 87: 24-32, 2007

52. Matsuzaki S, Canis M, Darcha C, Pouly JL and Mage G: HOXA-10 expression in the mid-secretory endometrium of infertile patients with either endometriosis, uterine fibromas or unexplained infertility. Hum Reprod 24: 3180-3187, 2009. 
53. Matsuzaki S, Darcha C, Maleysson E, Canis M and Mage G: Impaired down-regulation of E-cadherin and beta-catenin protein expression in endometrial epithelial cells in the mid-secretory endometrium of infertile patients with endometriosis. J Clin Endocrinol Metab 95: 3437-3445, 2010.

54. Matsuzaki S, Maleysson E and Darcha C: Analysis of matrix metalloproteinase-7 expression in eutopic and ectopic endometrium samples from patients with different forms of endometriosis. Hum Reprod 25: 742-750, 2010.

55. Rahmioglu N, Missmer SA, Montgomery GW and Zondervan KT: Insights into Assessing the Genetics of Endometriosis. Curr Obstet Gynecol Rep 1: 124-137, 2012.

56. Suarez-Quian CA, Goldstein SR, Pohida T, Smith PD, Peterson JI, Wellner E, Ghany M and Bonner RF: Laser capture microdissection of single cells from complex tissues. Biotechniques 26 : 328-335, 1999.
57. Aaltonen KE, Ebbesson A, Wigerup C and Hedenfalk I: Laser capture microdissection (LCM) and whole genome amplification (WGA) of DNA from normal breast tissue - optimization for genome wide array analyses. BMC Res Notes 4: 69, 2011.

58. Sabina J and Leamon JH: Bias in whole genome amplification: Causes and considerations. Methods Mol Biol 1347: 15-41, 2015.

59. Fend F, Specht K, Kremer M and Quintanilla-Martínez L: Laser capture microdissection in pathology. Methods Enzymol 356: 196-206, 2002.

60. Craven RA, Totty N, Harnden P, Selby PJ and Banks RE: Laser capture microdissection and two-dimensional polyacrylamide gel electrophoresis: Evaluation of tissue preparation and sample limitations. Am J Pathol 160: 815-822, 2002.

61. Matsuzaki S, Canis M and Mage G: Use of laser capture microdissection in studying hormone-dependent diseases: Endometriosis. Methods Mol Biol 590: 295-306, 2009. 